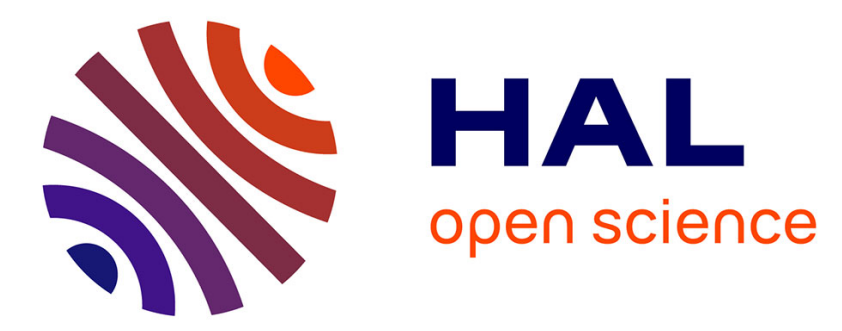

\title{
Electron energy loss measurements on the gold-silicon interface.
}

\author{
F. Salvan, A. Cros, J. Derrien
}

\section{To cite this version:}

F. Salvan, A. Cros, J. Derrien. Electron energy loss measurements on the gold-silicon interface.. Journal de Physique Lettres, 1980, 41 (14), pp.337-340. 10.1051/jphyslet:019800041014033700 . jpa00231793

\section{HAL Id: jpa-00231793 https://hal.science/jpa-00231793}

Submitted on 1 Jan 1980

HAL is a multi-disciplinary open access archive for the deposit and dissemination of scientific research documents, whether they are published or not. The documents may come from teaching and research institutions in France or abroad, or from public or private research centers.
L'archive ouverte pluridisciplinaire HAL, est destinée au dépôt et à la diffusion de documents scientifiques de niveau recherche, publiés ou non, émanant des établissements d'enseignement et de recherche français ou étrangers, des laboratoires publics ou privés. 


\title{
Electron energy loss measurements on the gold-silicon interface.
}

\author{
F. Salvan $\left({ }^{*}\right)$, A. Cros $\left({ }^{*}\right)$ and J. Derrien $\left({ }^{* *}\right)$ \\ Faculté des Sciences de Luminy, Département de Physique, Case 901, 13288 Marseille Cedex 2, France
}

(Reçu le 12 mars 1980, révisé le 12 mai, accepté le 27 mai 1980)

\begin{abstract}
Résumé. - Des films d'or déposés à température ambiante sur du silicium sont analysés par spectroscopie Auger et par pertes d'énergie, révélant ainsi l'existence de : 1) un interface diffus ; 2) un film d'or pur ; 3) une couche mixte or-silicium au-dessus du film. Les aspects des spectres de perte induits par la bande $d$ de l'or sont reliés aux propriétés électroniques des alliages or-silicium. Une estimation de la composition à la monocouche donne environ l'eutectique $\mathrm{Au}_{0,81} \mathrm{Si}_{0,19}$. Les effets de recuits sont aussi examinés.
\end{abstract}

\begin{abstract}
Gold films deposited at room temperatures on $\mathrm{Si}$ are analysed by Auger and electron energy loss spectroscopies which reveal the existence of : 1) a diffuse interface ; 2) a pure gold film ; 3) a mixed gold-silicon layer on top of the film. Loss spectra display gold $\mathrm{d}$ band features related to electronic properties of gold-silicon alloys. An estimation of the composition in the monolayer range gives nearly the eutectic $\mathrm{Au}_{0.81} \mathrm{Si}_{0.19}$. Annealing effects are also investigated.
\end{abstract}

The gold-silicon (Au-Si) interface is widely used in technology. In the past few years, it has been the object of many investigations. A good overview of its properties is of capital importance both on fundamental and technological points of view. Despite a large literature devoted to this subject, no definite understanding of its properties has been attained at the present time. The situation is very different from the $\mathrm{Ag}-\mathrm{Si}$ interface which is very abrupt [1] or from the $\mathrm{Pd}-\mathrm{Si}$ system whose properties are dominated by the formation of a definite compound [2]. However, some properties of thin gold films on $\mathrm{Si}$ are already well established. Bauer [3] and Le Lay et al. [4] studied the structural properties in the early stages of gold deposition on a $\mathrm{Si}$ (111) surface. The diffusion of $\mathrm{Si}$ through the gold films has been reported by Hiraki et al. [5] and Green and Bauer [6]. The electronic properties did not receive much attention up to now ; only recently published data from U.V. photoemission [7] and core level emission [8] gave some insight on this point.

The aim of this letter is to report some E.L.S. data on the Au-Si interface at the early stages of its formation and to relate them to its structural properties. The major features in the evolution of the spectra

(*) ERA C.N.R.S. 070373.

(**) ERA C.N.R.S. 070899. can be understood in terms of the electronic properties of gold-silicon alloys of varying composition. We also show as in the case of silver deposited on silicon that the E.L.S. spectra are very sensitive to the growth mechanisms which are different at room temperature and at temperatures higher than $400{ }^{\circ} \mathrm{C}$ [4].

Experiments were performed on $\mathrm{p}$ type $\mathrm{Si}$ surfaces $\left(10^{16}\right.$ boron atoms $\left./ \mathrm{cm}^{3}\right)$. The sample was cleaved in air along the (111) face and introduced in an U.H.V. chamber having LEED, Auger electron spectroscopy (A.E.S.) and E.L.S. facilities. Repetitive short heat treatments at $1000^{\circ} \mathrm{C}$ gave a clean $\mathrm{Si}$ surface as monitored by A.E.S. LEED patterns revealed also well ordered surfaces with very sharp $(7 \times 7)$ spots. Gold was deposited onto the sample from a Knudsen cell and the coverage $\theta$, defined as the ratio between the number of $\mathrm{Au}$ atoms and the number of Si surface atoms, was calibrated with a quartz microbalance. Coverage increments of $1 / 10$ allowed us to characterize the interface at the very beginning of its formation. At each stage of the deposition, A.E.S. and E.L.S. spectra were recorded. The incident electron energy in E.L.S. was $100 \mathrm{eV}$ and the back scattered electrons were analysed by means of a cylindrical mirror analyser (CMA) in the second derivative mode $-\mathrm{d}^{2} N / \mathrm{d} E^{2}$ of the reflected electron energy distribution. The energy resolution was $0.8 \mathrm{eV}$. LEED patterns were also checked. 
At room temperature, the evolution of the Auger spectra with increasing gold coverage gives the following results. The intensity of the Si peak at $92 \mathrm{eV}$ associated to a LVV Auger transition decreases in the range $0<\theta<4$. Near $\theta=4$, the peak splits into two components located at $90 \mathrm{eV}$ and $94 \mathrm{eV}$. Its lineshape then remains unchanged but its overall intensity decreases while the intensity of the gold peak at $69 \mathrm{eV}$ increases at higher coverages. Even at $\theta \sim 100$, A.E.S. indicates the presence of $\mathrm{Si}$ atoms on top of the gold film. In order to get some insight on the concentration profile, we proceeded to the sputtering of this film with argon ions and recorded the Auger spectra at fixed intervals during this treatment. The ion energy was $400 \mathrm{eV}$ and the ionic current density was $5 \mu \mathrm{A} / \mathrm{cm}^{2}$. From the calibration of the thickness of the deposit, we estimated the sputtering rate to fall at one monolayer $/ \mathrm{min}$. The profile obtained confirms the presence of : 1) a Si rich surface monolayer; 2) a pure gold film; 3) a diffuse interface of a few monolayers on top of the $\mathrm{Si}$ substrate.

The change in the Auger Si line reveals the modification of the electronic states in the valence electrons of Si surface atoms as in many Si-metal alloys [9] and allows an estimation of the composition of the top layer which is of the order of an $\mathrm{Au}-\mathrm{Si}$ eutectic alloy. The value which is usually admitted now for the eutectic composition is $\mathrm{Au}_{0.81} \mathrm{Si}_{0.19}$ [10] while many authors still use the old value $\mathrm{Au}_{0.69} \mathrm{Si}_{0.31}$ given by Hansen and Anderko [11]. We remark that the splitting is observed only at $\theta=4$ although the modification of the electronic states of $\mathrm{Si}$ surface atoms should already occur, as will be confirmed by E.L.S., at smaller coverages. In fact, its intensity is washed out by the large contribution of $\mathrm{Si}$ atoms in the subsurface. The progressive disappearance of the $7 \times 7$ LEED superstructure when $\mathrm{Au}$ is deposited suggests that the surface alloy is amorphous, a conclusion supported by the ability of $\mathrm{Si}$ and $\mathrm{Au}$ to form amorphous alloys.

The E.L.S. results are summarized in figure 1. For very low coverages, one sees immediate changes in the Si spectrum. The well-known bulk and surface structures corresponding to plasmon excitation and interband transitions [12] rapidly disappear when $\theta$ increases. Two peaks A $(7.5 \mathrm{eV})$ and B (about $11 \mathrm{eV})$ are seen at $\theta=1$. Somehow similar results are reported by Perfetti et al. [13]. Peak A shifts progressively towards $6 \mathrm{eV}$ when $\theta$ is increased and its position does not change for $\theta>12$. The unresolved and broad peak $B$ remains nearly at the same position in this range of $\theta$ values. The dashed curve (f) in figure 1 is a loss spectrum of a clean polycrystalline gold ribbon mounted on the sample holder. The spectrum obtained at $\theta \sim 100$ is still identical to spectrum (e) but different from spectrum (f) although the $6 \mathrm{eV}$ peak is present in both cases.

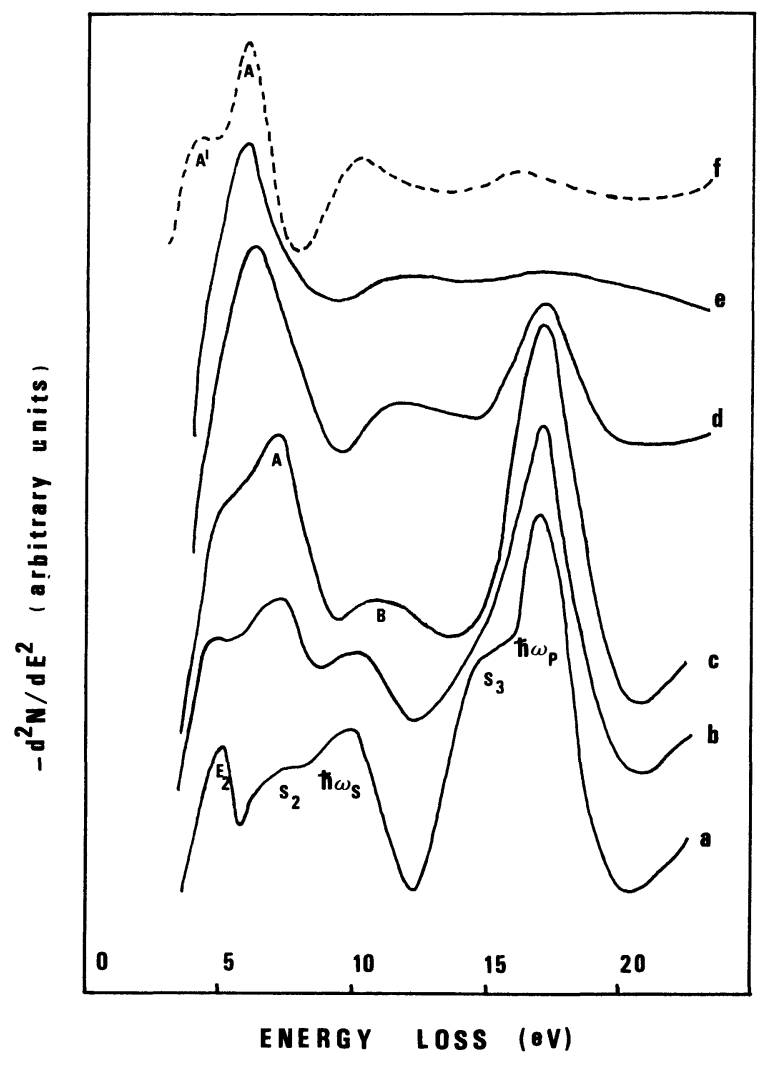

Fig. 1. - E.L.S. spectra of room temperature deposits. The primary electron energy was $100 \mathrm{eV} . N(E)$ is the reflected electron energy distribution. The modulation amplitude was $0.8 \mathrm{eV}$. Spectra were recorded in the second derivative mode of a CMA. (a) $7 \times 7$ clean surface; $\hbar \omega_{\mathrm{p}}=$ bulk silicon plasmon; $\hbar \omega_{\mathrm{g}}=$ surface plasmon; $S_{2}$ and $S_{3}=$ peaks due to electronic transitions from surface states; $\mathrm{E}_{2}=$ bulk silicon interband transition. (b) $\theta=\frac{1}{2}$; (c) $\theta=1$. Note the initial position of the $A$ peak for this gold-silicon mixed layer is at $7.5 \mathrm{eV}$. (d) $\theta=4$; (e) $\theta=12$. The A peak has shifted now to its final position characteristic of pure gold. The spectrum remains unchanged at higher coverages. (f) Spectrum of a pure gold sample.

The final position of peak $A$ corresponds to a characteristic loss of pure gold. The $\mathrm{d}$ band density of states in bulk Au displays two maxima (a) and ( $\left.\mathrm{a}^{\prime}\right)$ located respectively at $6 \mathrm{eV}$ and $4 \mathrm{eV}$ below the Fermi level. Peak $A$ in pure gold corresponds to a transition from maximum (a) in the $d$ band to the Fermi level in the sp conduction band. The expected transition $\mathbf{A}^{\prime}$ from $d$ band states $\left(a^{\prime}\right)$ to the Fermi level is not seen even at high $\theta$. Its energy is about $4 \mathrm{eV}$ and in loss spectra the intensity of this transition is known to be very sensitive to the structure of the gold film. This is due to possible screening effects caused by the small size of Au crystallites in the gold layer [14]. Another possible screening mechanism could come from the gold-silicon surface layer.

It is worth mentioning that the progressive shift of peak A occurs during the build up of the mixed gold-silicon layers revealed by the film composition profile. Above $\theta \sim 12$, gold layers are deposited and then peak $A$ remains located at the same energy position corresponding to the pure gold bulk value. 
It is thus attractive to relate the observed shift to electronic properties of amorphous gold-silicon alloys. In these alloys, $\mathrm{Si}$ is known to be metallic and when the composition $x$ of the system $\mathrm{Au}_{x} \mathrm{Si}_{1-x}$ is varied, a displacement of the $\mathrm{d}$ band relative to the Fermi level is observed [15]. This causes the energy of the first interband transition from $\mathrm{d}$ band to Fermi level $\left(\mathrm{A}^{\prime}\right)$ to increase when some amount of $\mathrm{Si}$ is admitted in pure gold and we expect a similar behaviour for the A peak. Therefore looking at the shift of the A peak, we can estimate the composition of the alloy, by comparison with the shift of the A peak in photoemission data obtained on well-known composition $\mathrm{Au}-\mathrm{Si}$ samples. This has been done using photoemission results of Hiraki et al. [5] where we compared the energies of the A peak for pure gold samples and for the eutectic alloy. In this manner, we found that the monolayer composition falls near the eutectic $\mathrm{Au}_{0.81} \mathrm{Si}_{0.19}$. This result seems to agree with the general behaviour of a metal semiconductor interface. Indeed Ottaviani et al. [16] have recently suggested that during the early formation of a Schottky barrier, an eutectic interfacial layer should play a large role. If $\theta$ is increased, further mixed goldsilicon layers are formed in which the $\mathrm{Au}$ concentration increases thus causing peak $\mathrm{A}$ to displace towards smaller energy up to $\theta \sim 12$. With overdose, gold layers are then deposited and peak $\mathrm{A}$ remains located at the same energy position, i.e. $6 \mathrm{eV}$.

Let us recall at this stage of the discussion that A.E.S. and E.L.S. signals integrate information on the electronic structure of atoms within an electron escape depth. Thus if spectral structures characteristic of both top layer and underlying layers within the probe depth are located at the same energy, subsurface effects will dominate. On the contrary, if no strong structure due to the underlayers is in the energy range analysed, outermost surface effects will prevail. This explains why the contribution of the surface alloy revealed by A.E.S. is hardly seen in the E.L.S. energy range of the strong interband transition near $6 \mathrm{eV}$ which is dominated by the underlying gold film. On the other hand, we believe that peak $B$ is due to the surface alloy because if we increase the escape depth by varying the incident electron energy, the intensity ratio $I_{B} / I_{A}$ from peak $B$ to peak $A$ decreases so that peak $B$ can be associated to the amorphous surface alloy. It is however impossible to assign it precisely either to a surface plasmon or to an electronic interband transition. Unfortunately, the band structure of gold-silicon alloys is not well-known so far to check this latter hypothesis. If on the contrary we assume that peak B is due to a surface plasmon, the value for the corresponding bulk plasmon should be $17 \mathrm{eV}$. This is very different from the $13 \mathrm{eV}$ predicted by the analysis of Hauser and coworkers [15].

Anyway, we would like to point out that the analysis of these authors is based on the rigid band model for metallic alloys and assumes a full metallic character of the Si valence electrons. Although this can give the general features of the $d$ band displacement in the sp conduction band, this cannot account for the results observed in photoemission [7]. In particular, Braicovich and coworkers report a change in the energy splitting of the two maxima (a) and $\left(a^{\prime}\right)$ of the $d$ band density of states when gold coverage is varied, which is unexplainable within this model.

If gold is deposited at temperatures $>400{ }^{\circ} \mathrm{C}$, the intensity variation of Auger peaks is characteristic of a Stranski-Krastanov growth mode where 3D crystallites can be observed [4]. No splitting occurs in the Auger Si peak even at large $\theta$. The evolution of loss spectra when $\theta$ increases is visible on figure 2 . No more drastic changes in the spectrum are seen when $\theta$ is $>2$. Spectra always present features characteristic of the monolayer range. This is due to the fact that even at high $\theta$ ( $>100$ layers), 3D clusters cover only $20 \%$ of the whole surface as revealed by scanning electron spectroscopy [17]. Thus the E.L.S. signal comes mainly from the regions of the first adsorbed layer uncovered by $3 \mathrm{D}$ clusters. In the same manner, annealing at $400{ }^{\circ} \mathrm{C}$ for a few minutes a film $(\theta \sim 100)$ previously deposited at room temperature, transformed this smooth film into $3 \mathrm{D}$ clusters on top of the first layer and the E.L.S. shows unambiguously this evolution [17]. This situation is very similar to that observed in Ag-Si [1].

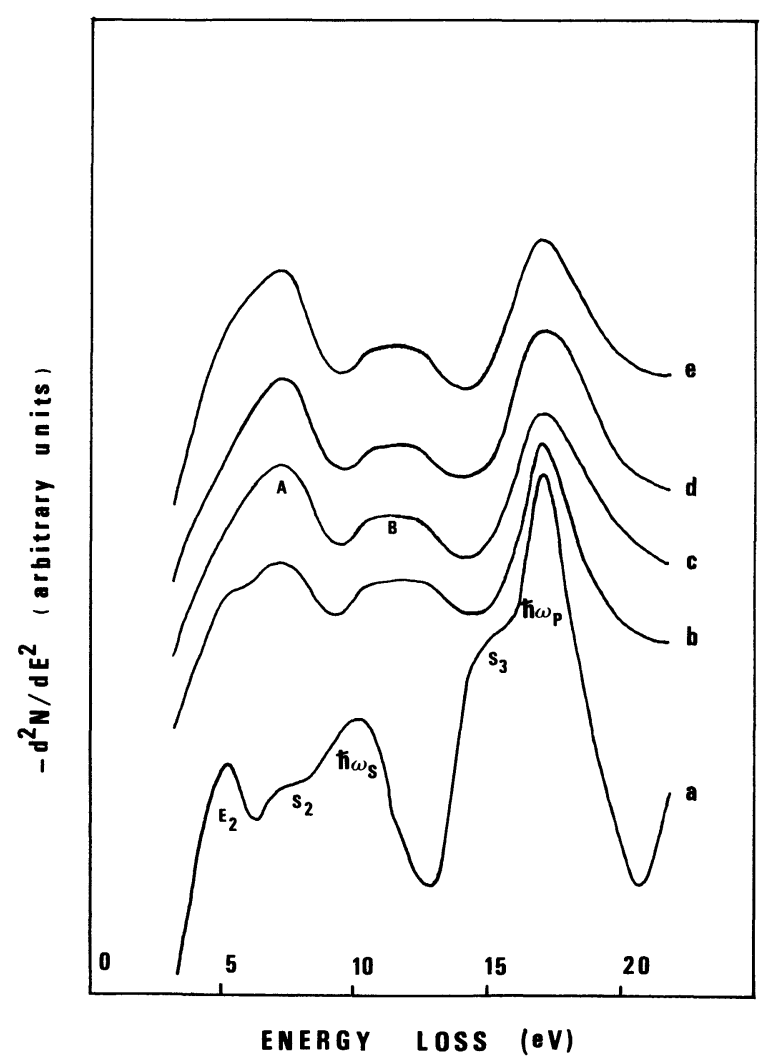

Fig. 2. - E.L.S. spectra at $T=400{ }^{\circ} \mathrm{C}$. Above $\theta=1$ almost no changes are observed. (a) $\theta=0$; (b) $\theta=1$; (c) $\theta=2$; (d) $\theta=10$; (e) $\theta=20$. 
Acknowledgments. - We are grateful to Prof. Kern, Drs. Gaspard and Le Lay for stimulating discussions and Manneville for skilful technical assistance.
Communications of results, prior to their publication, from Prof. Perfetti, Drs. Braicovich and Barth are very appreciated.

\section{References}

[1] Derrien, J., Le Lay, G. and Salvan, F., J. Physique Lett. [10] Castanet, R., Chastel, R. and Bergman, C., Mater. Sci. 39 (1978) L-287. Eng. 32 (1978) 93.

[2] Freeouf, J. L., Rubloff, G. W., Ho, P. S. and Kuan, T. S., Phys. Rev. Lett. 43 (1979) 1836.

[3] Bauer, E., J. Japan. Assoc. Crystal Growth 5 (1978) 49.

[4] Le Lay, G., Manneville, M. and Kern, R., Surf. Sci. 65 (1977) 261

[5] Hiraki, A. and Iwami, M., Japan. J. Appl. Phys. Suppl. 2 Pt 2 (1974) 749

[6] Green, A. K. and Bauer, E., J. Appl. Phys. 47 (1976) 1284.

[7] Braicovich, L., Garner, C. M., Skeath, P. R., Su, C. Y., Chye, P. W., Lindau, I. and Spicer, W. E., Phys. Rev. B 20 (1980) 5131.

[8] BarTh, J., DESY Report F41, 79/04, to be published.

[9] Hiraki, A., Iwami, M., Shinuzu, A. and Shuto, K., Mater. Sci. Eng. 23 (1976) 289.

[11] Hansen, M. and ANDERKo, K., Constitution of binary alloys (Mc Graw-Hill N. Y.) 1958.

[12] Rowe, J. E. and Ibach, H., Phys. Rev. Lett. 31 (1973) 102.

[13] Perfetti, P., Nannarone, S., Patella, F., Quaresima, C. and Savola, A., European Conference on the Physics of Semicond. surfaces and interfaces, Paris (1979).

[14] Breuer, K., Phys. Status Solidi (b) 91 (1979) K 69.

[15] Hauser, F., Zirke, R. J., TAuc, J., Hauser, J. J. and Nagel, R. S., Phys. Rev. B 19 (1979) 6331.

[16] Ottaviani, G., Tu, K. N. and Mayer, J. W., Phys. Rev. Lett. 44 (1980) 284.

[17] Cros, A., Derrien, J., Salvan, F. and Gaspard, J. P., Proceedings of the 3rd European Conference on Surface Science (ECOSS III), sept. 80 (to be published). 